\title{
Essential Concepts in Sociology
}

\author{
Anthony Giddens and Philip Sutton \\ Cambridge, UK: Polity Press, 2014. 240 pages.
}

My review of this book is not the outcome of my simple reading of it, but of translating it into Arabic. Its 240 pages identify and discuss sixty-seven essential sociological concepts, most notably those core concepts and ideas that allow sociologists to make sense of societies, even though our understanding of these concepts is constantly evolving and changing. The two sociologists have arranged their book in the following sections - working definition, origins of the concept, meaning and interpretation, critical points and, continuing relevance - and its contents into ten themes. Between the first theme of "Thinking Sociologically" and the last theme of "Political Sociology," a variety of other themes are discussed, among them "Structures of Societies," "Interaction and Communication," "Health, Illness, and the Body," and "Crime and Social Control." The authors use this arrangement to provide a portrait of sociology through its essential concepts, ranging from capitalism, identity, and deviance to citizenship, the environment, and intersectionality. The concepts of each theme are arranged alphabetically so that they may be analyzed, discussed, and debated.

Sociological literature shows the important relationship between concepts and theories: given that concepts are labels that refer to relations or descriptive properties, they are not statements and therefore are neither true nor false. They simply furnish the vocabulary of a theory and identify its subject matter. When concepts are interrelated in a scheme, a theory begins to emerge. 
In essence, two factors motivated me to write this review. First, this book covers the analysis and discussion of the essential concepts of contemporary sociology. I have a strong interest in concepts, for during my academic carrier I have invented some concepts for Arab sociology based upon the Arab social milieu particularly in the Maghreb (e.g., the Other Underdevelopment and Conspiring Bilingualism) and my personal intellectual curiosity has led me to create the concept/theory of "Man: The Three-Dimensional Being."

Second, I wish to provide access to sociologists in particular to get familiar with all of the sociological concepts presented and discussed in this book, for the wealth of information contained in it is bound to widen the horizons of both them and their students and improve their understanding and explanation of things and phenomena.

The book, written in a clear and jargon-free style, introduces a careful selection of essential concepts that have helped shape - and continue to do so - sociology and other disciplines. Going beyond the usual brief dictionary-style definitions, the authors offer an extended discussion of each concept that locates it both in its historical and theoretical contexts, explores its main meanings in use, puts forward some relevant criticisms, and points out to readers its ongoing development in contemporary research and theorizing. Such an organized profile may allow one to say that this book is not only a brief dictionary of sociological concepts, but also a thought-provoking reference work that makes an important contribution to the knowledge acquisition of basic constituents of sociology itself as a scientific discipline. As mentioned earlier, all sciences are born and achieve legitimacy once they first develop concepts and then use them to derive theories. Sociology sees that the relation between the two is very close, for concepts offer researchers the vocabulary that may result in the emergence of a theory as well as the determination of its subject matter.

This book is a strong cross-checking intellectual exercise of the state of sociology today. Focusing on sixty-seven sociological concepts through the above-mentioned analytical frame of the five-scale method offers readers adequate knowledge about the state of both the new and old sociological concepts and, consequently, about the current state of the discipline itself, since a given discipline core concepts reflects its current state. By underlining the pluses and the minuses of each concept, particularly in the sections of (critical points and continuing relevance), the authors implicitly evaluate the discipline of contemporary sociology as a whole. Despite their numerous criticisms of many concepts, they have not cited any of them as irrelevant to modern sociology. This is in line with the title's implicit meaning, where the 
adjective essential is taken to mean necessary. In other words, all of the concepts reviewed in the book remain necessary and valid.

Given the large number of concepts reviewed, I decided to choose only a few in order to familiarize the readers with how the authors have discussed them. This presentation is strictly limited to the authors' views expressed in item 4 (critical points) and item 5 (continuing relevance) of their five-item scale method of analysis. Consequently, I offer below a brief summary of their views of the following sociological concepts: ideal type, structure/agency, risk, intersectionality, social models of disability, and citizenship.

Giddens and Sutton summarize the criticisms of Max Weber's (d. 1920) concept of ideal-type as follows: Norbert Elias (d. 1990) believed that sociologists should study "real types" or empirical cases instead of spending a lot of time constructing ideal-types. Yet, the authors point out that the problem with ideal-types has to do more with how they are used rather than with the concept itself. Ultimately, ideal-types are good heuristic tools that stimulate research and help one gain better understanding and explanation of social phenomena.

The main criticism of Ulrich Beck's (d. 2015) risk theory comes from its exaggeration. For instance, neither empirical research nor Europe's Green political parties, for instance, support his claims. Furthermore, some critics see risk theory as being rather naïve about the concept of risk because it varies across cultures. In terms of concept relevance, recent global social changes have led more to states of uncertainty and less reliance on habitual ways of life. Consequently, sensitivity to risk appears to be increasing, which is compatible with Judith Green's remarks that the concept of risk has been very useful in her field of medical sociology.

The new concept of intersectionality raises criticisms among sociologists: how many inequality and identity categories can be included in the analysis using this specific concept? This gives rise to the "et cetera problem," whereby "etc." is added to class, gender, and "race" to indicate the presence of other influential factors involved in the process of intersectionality. The second criticism derives from the question as to whether the different forces are of equal weight in terms of shaping people's lives.

This concept's continuing relevance has become more important not only in understanding the differentiated experience of poverty, but also of social life as a whole. As a result, some sociologists have recently suggested that social policy must take into account intersectionality if legislation designed to ensure equality is to have a realistic chance of success. 
According to the authors, the concept of citizenship is coming under a great deal of criticism. Its very conceptualization by T. H. Marshall (d. 1981) is British made, a post hoc description rather than a genuine explanation. Furthermore, this conceptualization does not clarify why civil rights had to lead to political rights, which then had to lead to social rights. Many indicators show that citizenship is never firmly established, for it can potentially be reversed. Following the financial crisis of 2008, many governments cut back on public spending, which led to a change in the content of social citizenship. But despite this, Giddens and Sutton believe that the concept of citizenship remains sound. A current political debate is rethinking how to enable citizens to become more active as a means of reinvigorating politics and community life.

Advocates of the social model concept as providing solutions to physical and intellectual disabilities are faced with numerous criticisms. Some assert that it pays no attention to the often painful or uncomfortable experience of the impairment itself. As such, others argue that intellectual or physical impairment makes it impossible for people to participate fully in society and that social changes cannot remove this reality. On the other hand, its proponents call for it to be strongly supported because there appears to be no forthcoming alternative to challenge it. The use of this model has transformed the concept of disability itself in societies. As such, the emergence of the sociology of disability was made possible only after introducing the concept of the social model.

In the analysis of the concept of structure/agency dichotomy, the authors show that Pierre Bourdieu (d. 2002) sides more with the structure through his concept of "habitus," whereas Giddens' structuration theory sees agency as of more importance. While these two sociologists insist on the inevitable interaction between the two, Giddens remains silent on those elements that enable agency to influence and even chage the structure. In my opinion, this silence is likely due to the sociologists' lack of an epistemological outlook that views agency as a full cultural being (having language, thought, religion, knowledge/science, cultural values and norms). ${ }^{1}$ These cultural symbols (CS) permit humans to both establish and change the structures of their societies. Neglecting the crucial importance of CS in the contemporary social sciences has led their paradigms to look at Man as Homo Economicus or Homo Politicus or Homo Sociologus, but not as Homo Culturus, which is basic to conceive of the very emergence of the three other paradigms.

I end this review with the discussion of the concept of science in contemporary sociology. In the past, this particular concept has faced criticism 
by philosophers of science. The phenomena of "scientific revolutions" are no longer considered to be only the outcome of accumulative scientific discoveries; rather, according to Thomas Khun (d. 1996), they could be the result of surprising new paradigms because scientific revolutions occur when a scientist goes beyond a given paradigm and replaces it with a new paradigm. Ibn Khaldun's (d. 1406) invention of his new science ('ilm al-'umrān albashari [the science of human civilization]) can be cited as a reliable example, for he established it after strongly criticizing the existing paradigms of Muslim historians. As such, his new paradigm, represented by his Muqaddimah's vision, is divorced epistemologically and intellectually from the paradigms of others in the field of his time and before.

\section{Endnote}

1. M. Dhaouadi, Cultural Sociology within Innovative Treatise: Islamic Insights on Human Symbols (Lanham, MD: University Press of America, 2013),

Mahmoud Dhaouadi

Professor of Sociology

University of Tunis, Tunis, Tunisia 